\title{
Numerical Study of Motion of a Cylinder Filled with Water on an Inclined Plane using Scilab
}

\author{
Marini Amalia Ocvianti, Yudhiakto Pramudya*, and Moh Irma Sukarelawan \\ Physics Education Master Program, Universitas Ahmad Dahlan, Jalan Pramuka 42, Sidik, Umbulharjo, Yogyakarta 55161, Indonesia
}

\begin{abstract}
The velocity of the rolling motion is influenced by the shape of the object and its rotating axis. The cylinder motion on inclined plane has been investigated by number of research. However, the water filled cylinder need to be investigated further especially on the possibility moving sliding and rolling. Numerical study has been carried out on water filled cylinder modelling of frictionless sliding motion of point object, frictionless rolling motion, and rolling motion with friction on an inclined plane. By using the Euler method, data processing is carried out with the Scilab application. The resulting graph from running Scilab coding is a graph of $v$ vs $t$ and $x$ vs $t$. We found the frictionless sliding motion produces the greatest velocity and distance because it is not influenced by friction and the object's moment of inertia. Solid cylinder rolling with friction on an inclined plane produces the smallest velocity and distance due to the influence of friction and the moment of inertia of the object. These results indicate that a water filled cylinder can be considered a solid cylinder if ignoring all internal motion of water inside the cylinder.
\end{abstract}

Keywords: Cylinder; Rolling; Inclined plane; Scilab

*Corresponding author: yudhiakto.pramudya@pfis.uad.ac.id

Article history: Received 4 Maret 2021, Accepted 19 Agustus 2021, Published October 2021. http://dx.doi.org/10.12962/j24604682.v17i3.8853

2460-4682 (c)Departemen Fisika, FSAD-ITS

\section{INTRODUCTION}

If we observe the motion of the object, there is rotation and translation motion. Hence, the motion is a combination of translational and rotational motion. An object at rest will move only if a force acts on it. An object that is moving will experience a change in velocity when the object is also subjected to a force. This is an expression of Newton's second law. The same applies to rotational motion. An object at rest will rotate if the object works a quantity called the moment of force or torque. An object that is rotating will experience a change in angular velocity if the force moment is also applied to it.

Rolling motion is a combination of translational and rotational motion. Translational motion shows the change in the position of an object from its original position, while rotational motion shows the rotation of an object about the rotating axis. This combination of translational and rotational motion can be used to determine various variables in rolling motion.

Experiments were carried out to determine the moment of inertia of a solid cylinder with an experiment of rolling motion on an inclined plane [1], a simple model of a cylinder filled with water rolling on an inclined plane [2], determining the motion of a solid cylinder on an inclined plane using Arduino [3], and analyzing a solid ball rolling on an inclined plane in liquid [4]. The flow characteristics and fluid forces experienced by a body rolling down an inclined plane under gravity are examined through numerical modelling [5]. In this research, modeling is used for a cylinder filled with water mov- ing on an inclined plane. The water filled bottle is modeled as body moving without any internal motion. This first model is known as frictionless rolling motion of rigid solid cylinder model. The frictionless state prevent the turbulence and any internal drag between water and inner surface of cylinder. Another model is the model sliding motion without friction. The third model is the rolling motion with friction.

\section{METHOD}

\section{A. Cylindrical Motion on Inclined Plane}

Fig. 1 shows a diagram of the force on a cylinder filled with water rolling on an inclined plane. In translational motion, for cylinder that move on an inclined plane based on Newton's Second Law as described in Eqs. 1 and 2.

$$
\begin{gathered}
\sum F=m a \\
m g \sin \theta-f=m a
\end{gathered}
$$

where $m$ is the mass of the cylinder, $g$ is the acceleration due to gravity of the earth, $a$ is the acceleration of the motion of the cylinder, $\theta$ is the inclined plane angle of the path, and $f$ is the friction force between the plane and the cylinder.

Rotational motion occurs when a working object has a quantity called the moment of force or torque $(\tau)$. Torque produces rotational acceleration. For a rotational motion to 


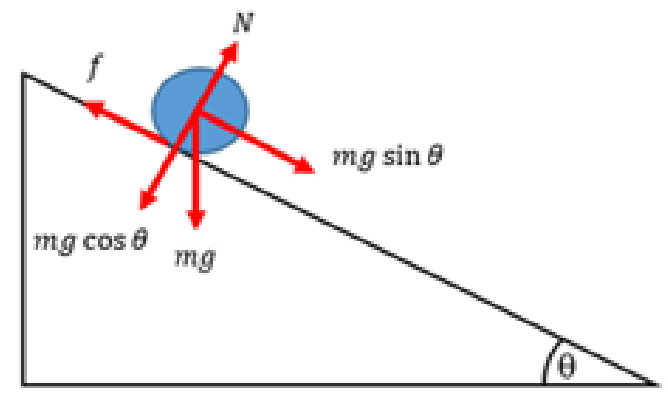

FIG. 1: The forces on the rolling cylinder on an inclined plane.

the center of mass of a cylinder, the torque whose direction is perpendicular to the axis of rotation is expressed as Eq. 3.

$$
\tau=r f
$$

Newton's second law of rotational motion is expressed by Eq. 4.

$$
\tau=I \alpha
$$

The angular acceleration $(\alpha)$ in the rotational motion of an object with radius $r$ is given by Eq. 5 .

$$
\alpha=\frac{a}{r}
$$

The moment of inertia of an object with mass $m$ and radius $r$ is generally expressed as

$$
I=k m r^{2}
$$

with $k$ is the moment of inertia coefficient, for the solid cylinder is $\frac{1}{2}$. By substituting Eqs. 5 and 6 into Eq. 4, then connecting with Eq. 3, we get Eq. 7 .

$$
f=\frac{1}{2} m a
$$

Eq. 7 is substituted into Eq. 2, then it will be obtained Eq. 8 .

$$
a=\frac{2}{3} g \sin \theta
$$

Since acceleration $a$ is the derivative of velocity to time, Eq. 8 can be expressed as Eq. 9 .

$$
\frac{d v}{d t}=\frac{2}{3} g \sin \theta
$$

Another approach to study the motion, the energy conservation analysis can be performed. This is the model of frictionless sliding motion. Based on the law of conservation of mechanical energy on the motion of an object on an inclined plane, the object that is moving with an initial velocity equal to zero will satisfy energy conservation as described in Eq. 10 .

$$
\frac{1}{2} m v^{2}=m g h
$$

where $m$ is the object's mass, $v$ is the object's velocity when it arrives underneath, and $h$ is the initial height of the object. The $h$ is expressed as Eq. 11.

$$
h=l \sin \theta
$$

where $l$ is the length of the object's path. Then, by substituting Eq. 11 to Eq. 10, we obtained Eq. 12.

$$
\frac{1}{2} v^{2}=g l \sin \theta
$$

As it is known that the acceleration of an object moving on an inclined plane is constant, so the kinematic equation that describes the acceleration of an object moving from rest in the constant acceleration approach is describes as Eq. 13.

$$
a l=\frac{v^{2}}{2}
$$

When combined with Eq. 12, it leads to the following expression for linear acceleration of the sliding point

$$
a=g \sin \theta
$$

Eq. 14 can be expressed as

$$
\frac{d v}{d t}=g \sin \theta
$$

The motion of cylinder on inclined plane can be studied more detail involving the density and the friction force. For the solid cylinder rolling on an inclined plane in the liquid as shown in Fig. 1, it is stated by Verekar [4] as

$$
\left(1.4 \rho+C_{a}\right) \frac{d v}{d t}=(\rho-1) g \sin \theta-C_{d} \frac{3}{4} \frac{v^{2}}{D}
$$

The equation is basically the equation of motion as described by Newton Law. It consist of gravity force acting on mass of cylinder and the drag force. The $\rho$ is the ratio between the density of the cylinder and the density of the liquid, $\mathrm{C}_{a}$ is the coefficient of added mass, $\mathrm{C}_{d}$ is the coefficient of drag, and $D$ is the diameter of the cylinder. For a cylinder filled with water rolling in the air, the equation of motion is Eq. 17. Hence, the $\rho$ is the ratio between the density of the cylinder and the density of air.

$$
\begin{gathered}
(1.4 \rho) \frac{d v}{d t}=(\rho-1) g \sin \theta \\
\frac{d v}{d t}=\frac{(\rho-1) g \sin \theta}{1.4 \rho}
\end{gathered}
$$

The assuming condition is that there is no frictional force between the water and the cylinder wall. This means that water does not rotate. Cylinders are considered solid with water as the filling material. 


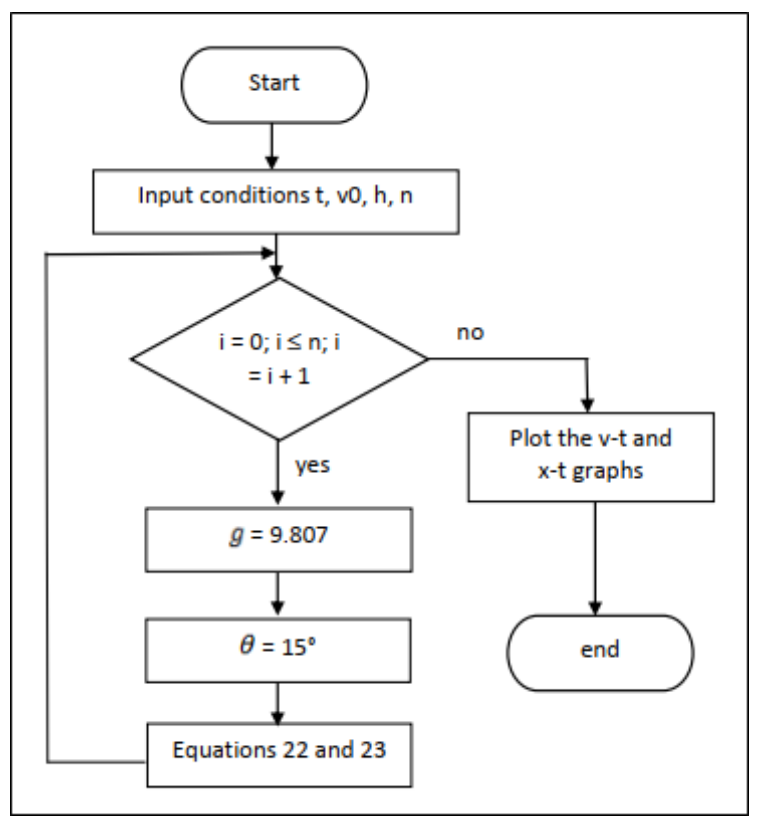

FIG. 2: Flow chart of numerical data processing for the motion of a frictionless rolling solid cylinder and frictionless sliding point object.

\section{B. Numerical Study Using Scilab}

Scilab is a software developed for numerical computation and data visualization needed in the field of science and engineering. The main advantage of Scilab is that it can be downloaded for free (freeware) under the CeCILL license, and is available for various operating systems such as Windows, Mac OS/X, Unix and Linux. Scilab is available on GNU/Linux, Mac OS X and Windows operating systems. Scilab provides hundreds of mathematical functions. This software has a high level programming language and can access data structures, 2D plots, 3D plots and graphical functions.

Numeric is a symbol or a collection of symbols that represent a number. By using Eqs. 9, 15, and 18, analysis is carried out in the Scilab program using the Euler method of first order differential equation models. Eq. 9 is used for modelling the rolling cylinder motion on an inclined plane, Eq. 15 is used for linear acceleration of sliding point, and Eq. 18 is used for rolling motion of cylinder filled with water.

Numerical data processing requires the support of a computer with specifications that match the program used, namely Scilab. There are several choices of types of Scilab programs that can be downloaded, namely 32 bit and 64 bit types.

Numerical completion method Using Euler's method. Euler's method is a method used to solve ordinary differential equations. This method also known as the one-step method and mathematically is represented as

$$
y_{i+1}=y_{i}+m h
$$

The slope $m$ is used to extrapolate the old value $y_{i}$ to the new value $y_{(i+1)}$ in the interval $h$. The gradient is

$$
m=f\left(x_{i}, y_{i}\right)
$$

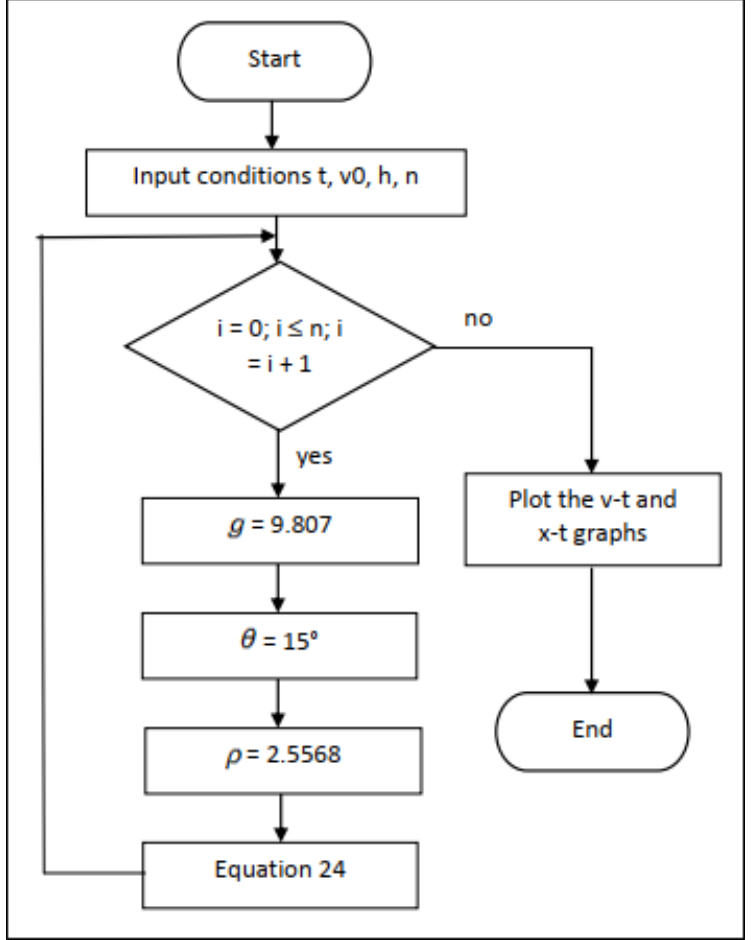

FIG. 3: Flow chart of numerical data processing of rolling motion of a cylinder with friction.

So that the gradient in Eq. 19 can be written as

$$
y_{i+1}=y_{i}+f\left(x_{i}, y_{i}\right) h
$$

So the new $y$-value is estimated based on the slope of the curve, equal to the first derivative at point $x$, to extrapolate the old $y$-value linearly over the interval $h$ to the new $y$-value.

Based on Eqs. 9, 15, and 18 which will be analyzed numerically in the Scilab program using the Euler method, the obtained equation is

$$
\begin{gathered}
v_{i+1}=v_{i}+\frac{2}{3} g \sin \theta \Delta t \\
v_{i+1}=v_{i}+g \sin \theta \Delta t \\
v_{i+1}=v_{i}+\frac{(\rho-1) g \sin \theta}{1.4 \rho} \Delta t
\end{gathered}
$$

From Eqs. 22, 23, and 24, the results will be compared based on the graph analysis of velocity versus time obtained. Eq. 22 is Euler's approximation for the motion of a frictionless rolling solid cylinder, Eq. 23 is an approximation for the motion of a frictionless sliding point object, while Eq. 24 is an approximation for a rolling cylinder motion with friction. To graph distance versus time, we use Eq. 25.

$$
x_{i+1}=x_{i}+v_{i} \Delta t
$$




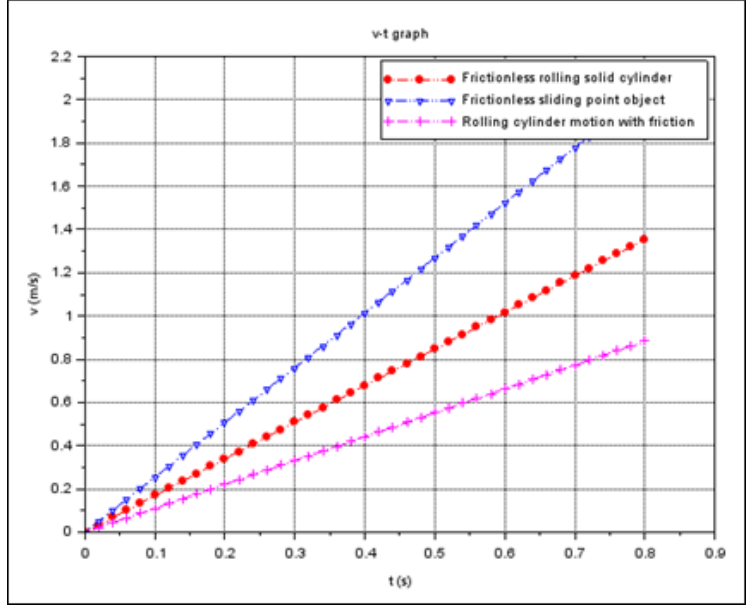

FIG. 4: The graph of $v$ - $t$, for rolling motion of a frictionless solid cylinder, frictionless sliding point object, and rolling motion of a cylinder with friction.

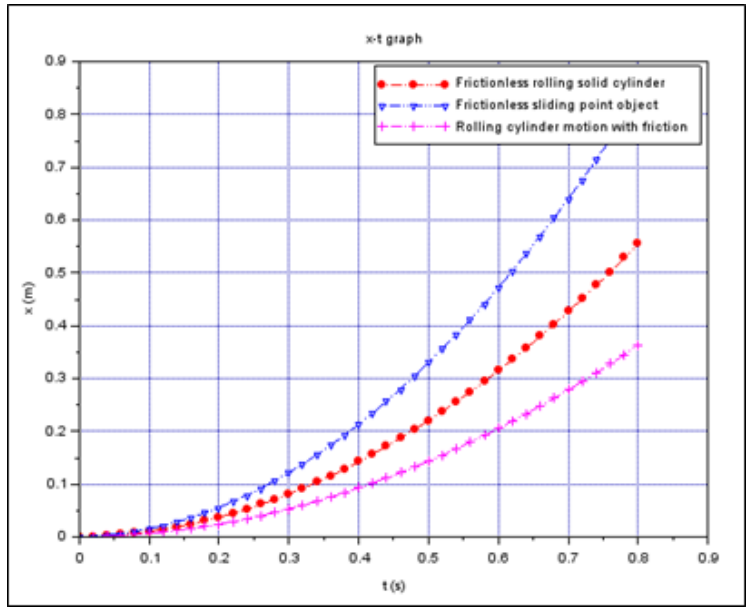

FIG. 5: The graph of $x$ - $t$, for rolling motion of a frictionless solid cylinder, frictionless sliding point object, and rolling motion of a cylinder with friction.

\section{RESULTS AND DISCUSSION}

Numerical data processing uses the Euler method in the Scilab program for modeling data. Motion of a cylinder filled with water on an inclined plane uses the data for Earth's gravity $g=9.807 \mathrm{~m} . \mathrm{s}^{-2}$, angle $\theta=15^{\circ}$, initial velocity $v_{0}=0.1$ $\mathrm{ms}^{-1},=0.1 \mathrm{~s}, \rho=2.5568$, and $l=1 \mathrm{~m}$. The value of $\rho$ was obtained from Ariefka's research in 2019. The flow chart of numerical data processing is shown in Fig. 2 and 3. After running Scilab coding, the graph of $v$ versus $t$ is obtained as shown in Fig. 4.

The velocity of cylinder of three different approach are shown in Fig. 4. From these results, it can be seen that for a frictionless sliding point object on an inclined plane has a greater speed than others because it is unaffected by friction and moment of inertia of the object. Meanwhile, motion of a frictionless rolling solid cylinder that rolls on an inclined plane produces a smaller velocity and the moment of inertia of the object. Furthermore, for a cylinder rolling on an inclined plane with friction produces the lowest speed compared to the other two motion objects. This is due to the friction factor and density of the cylinder. The graphical profile of $x$ versus $t$ from running Scilab coding is shown in Fig. 5.

The position as function time can be graphed as shown in Fig. 5. From these results, it is known that there are similarities in the results regarding the velocity and distance obtained from the three conditions being modeled. Since there is no friction and no rolling motion, the point object sliding on an inclined plane has a greater distance than others. The rolling cylinder model generates result of position less than the position of frictionless sliding motion model. This is due to the moment of inertia of cylinder. The involvement of friction on the model produce the least distance compared to the others model. Hence, the water filled cylinder can be modeled by frictionless sliding point object motion, frictionless rolling solid cylinder motion, and the rolling solid cylinder motion with friction. The energy consumed by friction and rolling motion play important role in acceleration. The velocity and the position are determined by the behavior of the acceleration of each model. However, the profile of velocity and position need to be verified by experimental results.

\section{SUMMARY}

Based on the results of a numerical study using a Scilab, it is found that the water filled cylinder can be modeled by frictionless sliding point object motion, frictionless rolling solid cylinder motion, and the rolling solid cylinder motion with friction. The frictionless sliding cylinder on an inclined plane has a greatest velocity and distance because they are unaffected by friction and moment of inertia. These results indicate that the water filled cylinder can be considered a solid cylinder if we neglecting all internal motion of water inside the cylinder.
[1] E. S. Kurniawan and R. Oktova, "Penentuan Momen Kelembaman Silinder Pejal dengan Percobaan Bidang Miring," Berkala Fisika Indonesia, vol. 3(1), pp. 6-16, 2011.

[2] S. Lin, N. Hu, T. Yao, C. Chu, S. Babb, J. Cohen, G. Sangiovanni, S. Watt, D. Weisman, J. Klep, W. J. Welecki, E. S. Welecki, and P. S. Welecki, "Simple Model of a Rolling WaterFilled Bottle on an Inclined Ramp," The Physics Teacher, vol.
53, pp. 548-549, 2015

[3] W. Saputra, and Y. Pramudya, "Pengembangan Instrumentasi Penentuan Kecepatan Gerak Silinder Pejal Pada Bidang Miring Dengan Menggunakan Arduino," Jurnal Pendidikan Informatika dan Sains, vol. 8 (2), pp. 207-213, 2019.

[4] P. K. Verekar, and J. H. Arakeri, "Sphere Rolling Down an Incline Submerged in a Liquid," The 37th International 4th $\mathrm{Na}$ - 
tional Conference on Fluid Mechanics and Fluid Power, pp. $1-9,2010$.

[5] F. Y. Houdroge, K. Hourigan, T. Leweke, and M. C. Thompson, "Fluid- Structure Interaction of a Cylinder Rolling Down an Incline under Gravity," 19th Australasian Fluid Mechanics Conference, 2014.

[6] M. Abdullah, Fisika Dasar I, Institut Teknologi Bandung, pp. 629-664. 2016.

[7] R. Ariefka, "Studi Numerik Gerak Silinder di Bidang Miring dalam Air menggunakan Scilab," Thesis, Magister Pendidikan Fisika Universitas Ahmad Dahlan Yogyakarta, Indonesia, 2019.

[8] F. Aulia "Scilab," Laboratorium Informatika dan Komputer Teknik Elektro Universitas Brawijaya Malang. 2013.

[9] S. C. Chapra, and R. P. Canale, "Numerical Method for Engineers 7nd Ed," McGraw-Hill Book Co., New York. 2015; p. 576-640.

[10] Riswanto and Suharno, "Penentuan Koefisien Momen Inersia Bola Pejal Melalui Video Gerak pada Bidang Miring dengan Fitting Data," Prosiding Pertemuan Ilmiah XXVIII HFI Jateng DIY, pp. 31-34, 2014.

[11] J. Rosch, "The Effects of Fluid in a Can Rolling Down an Incline," Physics Departement, The Collage of Wooster, Ohio; 2006.

[12] S. B. Sasongko, "Metode Numerik dengan Scilab," C.V. Andi Offset, Yogyakarta, 2010.

[13] R. Gabl, T. Davey, and D. M. Ingram, "Roll Motion of a Water Filled Floating Cylinder-Additional Experimental Verification," Water MDPI, vol. 12, pp. 2219, 2020.

[14] K. T. McDonald, "The Rolling Motion of a Half-Full Beer Can," Joseph Henry Laboratories, Princeton University, 2017.
[15] R. Cross, "Motion of An Inclined Cylinder on An Inclined Plane," Europian Journal of Physics, ResearchGate, 2015.

[16] E. Wibowo, Sutrisna, M. Rokhmat, E. Yuliza, Khairurrijal, and M. Abdullah, "Theoretical and Experimental Studies on a Cylinder Containing Granules Rolling Down an Inclined Plane," arXiv Cornell University, 2014.

[17] R. Ariefka, and Y. Pramudya, "The Study of Hollow Cylinder on Inclined Plane to Determine The Cylinder Moment of Inertia," UNNES Physics International Symposium Series, vol. 1170, pp. 012081, 2019.

[18] C. Zang, K. Soga, K. Kumar, Q. Sun, and F. Jin, "Numerical Study of a Sphere Descending along an Inclined Slope in a Liquid," Granular Matter, vol. 19:85, 2017.

[19] R.H. Hernandez, A. Vial, C. Barraud, "Motion of a Free Cylinder Inside a Rotating Water-Filled Drum," Article in Physics of Fluids, vol. 27(8), 2015.

[20] A.A Ivanova, and I. Kozlov, "Dynamics of a Fluid in a Rotating Horizontal Cylinder," Article in Fluid Dynamics, vol. 39(4), pp. 594-604, 2004.

[21] J. L. Gyeong, "Moment of Inertia of Liquid in a Tank," Article in Int. J. Nav. Archit. Ocean Eng, vol. 6, pp. 132-150, 2014.

[22] S. Arief, "Belajar Komputasi Numerik dan Komputasi Terapan dengan Scilab Online," Artikel di Ilmu Komputer.Com, 2019.

[23] R. Muda, et al., "Mengukur Kebenaran Konsep Momen Inersia dengan Penggelindingan Silinder pada Bidang Miring," Prosiding SKF, pp. 357-366, 2016.

[24] K. Yusuf, "Penentuan Koefisien Momen Inersia dengan Video Analisis," Prosiding Seminar Nasional Fisika dan Pendidikan Fisika Ke-6, vol. 6, no.1, pp. 174-178, 2015. 